\title{
Ações interdisciplinares no ensino de Física: pressupostos teóricos e revisão da literatura ${ }^{+*}$
}

Fabiane Beatriz Sestari ${ }^{1}$

Doutoranda do PPG Educação em Ciências - UFSM

Instituto Federal do Rio Grande do Sul

Isabel Krey Garcial ${ }^{1}$

Departamento de Física - Universidade Federal de Santa Maria

Maria Cecília Pereira Santarosa ${ }^{1}$

Departamento de Matemática - Universidade Federal de Santa Maria

Santa Maria - RS

\section{Resumo}

Tendo em vista a importância do tema interdisciplinaridade no contexto educacional e o seu caráter polissêmico, este trabalho objetivou discutir algumas definições sobre a temática, diferenciando a interdisciplinaridade de outros níveis de relação disciplinares. Além do aporte teórico apresentado, buscamos responder a seguinte pergunta: Como o Ensino de Física tem se articulado com outras áreas do conhecimento, na proposição de ações interdisciplinares ou em outros niveis de relações disciplinares? Para responder essa questão foco, realizamos um estudo de revisão sistemática da literatura adotando, como corpus de análise, artigos de dezesseis periódicos nacionais de Ensino de Física/Ciências, publicados entre 2006 e 2018. Empregamos a categorização temática segundo Bardin (2011), e através da exploração e transformação por padronização e equivalência as informações foram agrupadas em categorias. Além das categorias definidas à priori, emergiram desse processo classificações quanto à abordagem, natureza e objetivos da pesquisa organizados nas categorias: i) trabalhos que contemplaram propostas de atividades interdisciplinares com a Física, sem a utilização de metodologias especificas; ii) trabalhos que contemplaram estudos de natureza teórica, pressupostos legais sobre a temática, bem como

\footnotetext{
${ }^{+}$Interdisciplinary actions in Physics Teaching: theoretical assumptions and literature review

${ }^{*}$ Recebido: 25 de setembro de 2019.

Aceito: 16 de dezembro de 2020.

${ }^{1}$ E-mails: fabisestari@gmail.com; ikrey69@gmail.com; maria-cecilia.santarosa@ufsm.br
} 
concepções que educadores tem sobre o tema; iii) trabalhos que contemplaram propostas de atividades de ensino de Física a partir de temas geradores, abordagem temática CTS, Situações de Estudo e Ilhas Interdisciplinares de racionalidade; iv) trabalhos que apresentaram conceitos da Física em aplicações contextualizadas ou como ferramenta para outras áreas do conhecimento. Através da discussão dos resultados evidenciou-se o uso excessivo e indiscriminado do termo interdisciplinaridade como uma tentativa de contemplar as diretrizes educacionais e a escassez de trabalhos que apresentem propostas de ensino que integrem conceitos da Física com outras áreas do conhecimento tanto científico como técnico em consonância com as características destacadas pelo referencial teórico utilizado. Destaca-se também como resultado dessa revisão, a necessidade de aprofundamento teórico para fundamentar as práticas de ensino realizadas e de uma formação continuada que priorize a reflexão, a dialogicidade e o planejamento coletivo, bem como a importância de assumir a interdisciplinaridade como uma atitude de abertura frente ao objeto do conhecimento, incorporando os resultados de várias disciplinas.

Palavras-chave: Relações disciplinares; Interdisciplinaridade; Interdisciplinaridade em sala de aula; Ensino de Ciências e Física.

\begin{abstract}
In view of the importance of the interdisciplinary theme in the educational context and its polysemic character, this study aimed to discuss some definitions on the theme, differentiating interdisciplinarity from other levels of disciplinary relationship. In addition to the theoretical contribution presented, we seek to answer the following question: How has Physics Education been articulated with other areas of knowledge, in proposing interdisciplinary actions or at other levels of disciplinary relations? To answer this focus question, we conducted a systematic literature review study adopting, as corpus of analysis, articles from sixteen national journals on Physics / Science Education, published between 2006 and 2018. We use thematic categorization according to Bardin (2011), and through exploration and transformation by standardization and equivalence the information was grouped into categories. In addition to the categories defined a priori, classifications emerged from this process regarding the approach, nature and
\end{abstract}


objectives of the research organized in the categories: $i)$ works that included proposals for interdisciplinary activities with Physics without the use of specific methodologies; ii) works that included studies of a theoretical nature, legal assumptions about the theme, as well as conceptions that educators have about the theme; iii) works that contemplated proposals for teaching physics activities based on generating themes, thematic approach CTS, Study Situations and Interdisciplinary Islands of rationality; iv) works that presented Physics concepts in contextualized applications or as a tool for other areas of knowledge. Through the discussion of the results, the excessive and indiscriminate use of the term interdisciplinarity was evidenced as an attempt to contemplate the educational guidelines and the scarcity of works that present teaching proposals that integrate concepts of Physics with other areas of knowledge both scientific and technical in line with the characteristics highlighted by the theoretical framework used. It also stands out as a result of this review, the need for theoretical deepening to support the teaching practices carried out and for continued training that prioritizes reflection, dialogicity and collective planning, as well as the importance of taking interdisciplinarity as an open attitude towards the object of knowledge, incorporating the results of various disciplines.

Keywords: Disciplinary Relations; Interdisciplinarity; Interdisciplinarity in the Classroom; Physics and Science Teaching.

\section{Introdução}

A interdisciplinaridade apresenta-se como um dos temas bastante evidenciados no contexto educacional, tanto em documentos curriculares oficiais, como as Diretrizes Curriculares Nacionais da Educação Básica DCNEB (BRASIL, 2013) e os Parâmetros Curriculares Nacionais PCN (BRASIL, 1998), bem como nas pesquisas acadêmicas e em discussões voltadas ao currículo e ao planejamento na área de Ensino, nos diversos níveis de ensino e modalidades da educação básica. Entretanto, conforme destaca Fazenda (2011b, p. 11) apesar das reformas na educação brasileira apontarem a necessidade de uma proposição interdisciplinar, desde a década de 70, mesmo nas décadas subsequentes ainda apresenta compreensões equivocadas. A partir da década de 2000 passa a ser apontada, nesses documentos curriculares nacionais, não somente como uma possibilidade metodológica, mas como pressuposto norteador de toda a organização do currículo e pedagógico do processo de ensino e aprendizagem.

Apesar da intensa referência ao termo interdisciplinaridade, inclusive no discurso dos profissionais da educação, apresenta uma multiplicidade de concepções, o que pressupõem 
cautela na sua utilização e interpretação. Percebe-se que esta nomenclatura, assim como outras derivadas dos diversos níveis de relações disciplinares, têm sido utilizadas para nomear ações que nem sempre contemplam as características das relações/inter-relações, conforme será apresentado no decorrer desse trabalho, indicando uma banalização e modismo do uso deste termo.

Tendo em vista o caráter polissêmico do termo interdisciplinaridade e a importância da temática no contexto educacional, podemos destacar alguns questionamentos: Afinal, o que é interdisciplinaridade? Quais as características que diferenciam a interdisciplinaridade dos outros níveis das relações disciplinares? Qual(is) metodologia(s) caracteriza(m) um ensino interdisciplinar?

Além da importância de destacar aspectos conceituais e metodológicos da interdisciplinaridade, apresentamos como problemática principal dessa pesquisa: como o Ensino de Física tem se articulado com outras áreas do conhecimento, na proposição de ações interdisciplinares ou em outros níveis de relações disciplinares?

$\mathrm{Na}$ perspectiva de um conhecimento não fragmentado em "fatias de saber", poderíamos propor essa última pergunta da seguinte forma: como os conceitos físicos têm se articulado com conceitos de outras áreas do conhecimento em torno de situações-problema ou objetos de estudo? No entanto, mesmo para a proposição de ações interdisciplinares ou em outros níveis de relação disciplinar, no contexto educacional, habitualmente, obtém-se contribuições de esquemas conceituais dessa ou daquela disciplina, como se determinado conhecimento fosse "de posse das disciplinas".

Diante das inquietações expostas, objetivamos discutir nesse trabalho, algumas definições, sobre o termo interdisciplinaridade, apresentadas por autores com renomada experiência nessa temática, buscando também diferenciar a interdisciplinaridade dos outros níveis de relações disciplinares e caracterizar os pressupostos e metodologias indicadas para a proposição dessas ações.

Pesquisas sobre interdisciplinaridade como, por exemplo, no trabalho de Mozena e Ostermann (2014), apresentam um perfil das pesquisas na área de Ciências e a compreensão da área de pesquisa em ensino de ciências sobre a interdisciplinaridade no contexto escolar do nível médio. As autoras comparam também a incidência dos estudos sobre o tema no Brasil e fora do país, investigando características de seus pesquisadores. Resultados destacam a importância de investigar as proposições interdisciplinares que vêm sendo desenvolvidas por pesquisadores e docentes.

Com o intuito de responder a problemática principal, buscamos investigar através de uma revisão sistemática da literatura, as ações de caráter interdisciplinar propostas e implementadas no âmbito da Educação Básica, por professores de Ciência e de Física, contemplando campos conceituais da Física, ou situações-problema e objetos de estudo que demandem conhecimento de conceitos físicos.

Diante do exposto, na primeira parte deste artigo discutimos as distintas definições 
de interdisciplinaridade, contemplando outras relações e níveis disciplinares. Apesar de os autores não apresentarem uma definição exata e única sobre o termo, são unânimes em relação à unidade do conhecimento, na busca de compreender o mundo real, em contraposição a uma atuação pedagógica com o fracionamento do saber, desarticulado da realidade.

Sequencialmente, apresentamos o percurso metodológico da revisão de literatura, destacando e justificando a escolha dos periódicos utilizados, os critérios de seleção e a estruturação de categorias à priori. A partir da categorização dos trabalhos, apresentamos os resultados quantitativos obtidos e uma breve discussão desses resultados. Segue-se a discussão das categorias emergentes dessa pesquisa.

\section{Referencial Teórico}

O conceito de interdisciplinaridade tem estado presente nas diretrizes educacionais nacionais (BRASIL, 1998; 1999; 2013), inicialmente apresentada como um princípio pedagógico para orientar atividades que priorizem a unidade do conhecimento, na busca de compreender o mundo real, em contraposição a um ensino fragmentado e desarticulado da forma como se apresenta no cotidiano e também como um princípio norteador de todo o processo de ensino e aprendizagem. No entanto, a interdisciplinaridade que ganha espaço nesta perspectiva é, na realidade da escola, pouco compreendida em relação aos seus pressupostos e metodologias.

Devido ao seu caráter polissêmico, no contexto da pesquisa educacional, o termo interdisciplinaridade apresenta múltiplas possibilidades de interpretação e discurso, No entanto, geralmente é associado a um conceito, uma metodologia ou apresentado, segundo DCNEB (2013, p. 184) como uma "abordagem teórico-metodológica com ênfase no trabalho de integração das diferentes áreas do conhecimento".

A compartimentalização do conhecimento e a divisão dos saberes em disciplinas e subdisciplinas cada vez mais específicas dividem os conhecimentos e desencadeia uma superespecialização em áreas muito estreitas. Essa fragmentação especializada apresenta os conhecimentos desarticulados do todo dificultando a sua significação para o sujeito aprendiz. Em busca da totalidade do saber perdida, Japiassu (1976, p. 8) caracteriza a interdisciplinaridade como uma possibilidade de reunificar os saberes fragmentados em favor de uma interpretação global do mundo e aponta a interdisciplinaridade como recurso válido para superação da mencionada divisão cartesiana ${ }^{2}$ e como opção para superar a crise da superespecialização.

De acordo com Japiassu (op. cit., p. 32), a característica central da interdiscipli-

\footnotetext{
2 A origem da fragmentação do conhecimento é citada frequentemente na literatura como sendo cartesiana. Embora não haja consenso sobre essa origem, Descartes (1978) propõe no livro Discurso do Método que para se resolver uma questão complexa deve-se decompô-la em partes menores a fim de simplificar o problema. A união da resolução das partes daria a resolução do todo.
} 
naridade consiste no fato de que ela incorpora os resultados de várias disciplinas, tomandolhes de empréstimo esquemas conceituais e análise a fim de fazê-los integrar, depois de havêlos comparado e julgado. Salienta que a interdisciplinaridade se caracteriza na intensidade das trocas entre os especialistas e pelo grau de integração real das disciplinas no interior de um mesmo projeto.

Trazendo as palavras do autor para o contexto educacional, poderíamos caracterizar a interdisciplinaridade como a utilização ou empréstimo de saberes ou esquemas conceituais de diversas especialidades em torno de um mesmo evento, situação, objeto de estudo. Várias situações do cotidiano, por exemplo, podem ser explicadas utilizando-se da descrição de princípios físicos que ficam mais evidenciados na sua observação. No entanto, não se pode descartar a infinidade de outros elementos, lei e princípios, não pertencentes necessariamente ao arsenal de conceitos da Física, que explicam determinado fenômeno na sua totalidade. Uma determinada situação ${ }^{3}$, por mais simples e específica que pareça, não pode ser descrita e explicada unicamente através de conceitos físicos, ou químicos, ou de qualquer disciplina específica.

O trabalho interdisciplinar consiste, primordialmente, em lançar uma ponte para religar as fronteiras que haviam sido estabelecidas anteriormente entre as disciplinas com o objetivo preciso de assegurar a cada uma seu caráter propriamente positivo, segundo modos particulares e com resultados especificos. [...] O fundamento do espaço interdisciplinar deverá ser procurado na negação e na superação das fronteiras disciplinares (JAPIASSU, 1976, p. 75).

A descrição de um objeto de estudo ou explicação da ocorrência de um evento requer conhecimentos de diversas áreas, sem o julgamento de importância de conceitos de uma área ou de outra.

Japiassu (Ibid.) também defende que a interdisciplinaridade não pode ser apenas estudada, para adentrá-la precisa ser exercida. Ela se manifesta na atividade contínua de um grupo de pessoas que, embora diferentes, conseguem consolidar ações de coexistência pacífica e até de laços fraternos podendo criar espaço para surgir a cooperação e a solidariedade.

Jantsch e Bianchetti (2011, p. 20) denominam interdisciplinaridade como um objeto filosófico-científico. Na visão dos autores, a ação do sujeito sobre o objeto, é o fundamento principal da concepção relativa à interdisciplinaridade. Não aceitam a acepção iluminista que concebe a interdisciplinaridade como método capaz de tirar as ciências da caminhada em direção ao seu maior mal: a especialização; bem como a ideia dos trabalhos em equipe ou em parceria ${ }^{4}$ como forma capaz de superar a redução subjetivista da própria filosofia do sujeito. Outro aspecto não aceito pelos autores é de que o somatório de individualidades ou de

${ }^{3}$ Caracterizamos situação, nesse trabalho, um conjunto de conceitos, esquemas e invariantes que descrevem e explicam a sua ocorrência.

${ }^{4}$ A visão de interdisciplinaridade assentada no trabalho em equipe ou em parceria é proposta por Ivani Fazenda. 
sujeitos pensantes possa apreender a complexidade do problema/objeto.

Morin (2011), apesar de não defender exatamente o conceito Interdisciplinaridade também apresenta a importância da articulação entre o uno e o múltiplo ${ }^{5}$, a diversidade e a unidade, dentro de um contexto abrangente e global. Morin (2002) defende o conceito de interdisciplinaridade apoiado na complexidade, pautado em uma visão global de mundo, onde os aprendizes tenham aptidão para "articular, religar, contextualizar, situar-se num contexto e, se possível, globalizar, reunir os conhecimentos adquiridos" (Ibid., p. 29).

Pombo (2004) também contribui para definirmos interdisciplinaridade quando apresenta a perspectiva de que conhecimento se constrói com base numa realidade complexa que necessita dos saberes das diversas áreas do conhecimento, vencendo a fragmentação disciplinar e descontextualizada, priorizando um currículo integrado como compreensão global do conhecimento como uma construção coletiva. Metodologicamente, defende a contextualização da teoria ensinada em aplicações práticas.

Fazenda (2013, p. 22) considera a definição clássica, produzida em 1970 pelo Ceri Centro para Pesquisa e Inovação do Ensino - na qual interdisciplinaridade é definida como interação existente entre duas ou mais disciplinas, podendo encaminhar da simples comunicação das ideias até a integração mútua dos conceitos-chave da epistemologia, da terminologia, do procedimento, dos dados e da organização da pesquisa e do ensino, relacionando-os. Devido à sua ampla definição, é insuficiente tanto para fundamentar práticas interdisciplinares como para pensar em uma formação interdisciplinar de professores. Fourez (2001 apud FAZENDA, 2013, p. 22) sugere que, para conceber a interdisciplinaridade, podese proceder uma decodificação em ordem científica e social. A científica conduziria à construção do que se denominam saberes interdisciplinares associados à cientificidade, e a social ao desdobramento dos saberes científicos interdisciplinares às exigências sociais, políticas e econômicas. Lenoir (2001, apud FAZENDA, 2013, p. 23-24; 2012) aponta para o surgimento de uma terceira cultura legitimada como a do saber ser interdisciplinar que se explicita na inclusão da experiência docente em seu sentido, sua intencionalidade e sua funcionalidade, diferenciando o contexto científico do profissional e do prático.

Fazenda (2013, p. 26) ainda distingue interdisciplinaridade escolar, curricular, pedagógica ou didática da interdisciplinaridade científica. $\mathrm{Na}$ interdisciplinaridade escolar, de perspectiva educativa, as noções, finalidades, habilidades e técnicas visam a favorecer sobretudo o processo de aprendizagem, respeitando os saberes dos alunos e sua integração. A partir desse aspecto, apesar da indissociabilidade entre integração e interdisciplinaridade, ainda reafirma que são distintos.

Fazenda (2011a) considera a interdisciplinaridade como atitude a ser assumida no sentido de alterar hábitos já estabelecidos na compreensão do conhecimento. Deve estabelecer uma relação mútua de reciprocidade, assumindo uma atitude diferente frente a um objeto do

\footnotetext{
${ }^{5}$ Severino (2011, p. 139) destaca a necessidade de enfocar a relação entre a unidade e a multiplicidade, no sentido de que não predomine uma polaridade entre elas e nem mesmo um equilíbrio. Coloca a necessidade de conviver com as duas perspectivas, ressaltando as características simultâneas do ser de uno e múltiplo.
} 
conhecimento, ou seja,

[...] é a substituição de uma concepção fragmentária para unitária do ser humano. [...] É uma atitude de abertura, não preconceituosa, em que todo o conhecimento é igualmente importante. [...] Assim sendo, pressupõe uma atitude engajada, um comprometimento pessoal (Ibid., p. 10-11).

Uma visão interdisciplinar, segundo Fazenda (op. cit., p. 11) implica mudanças nos aspectos pedagógicos. Coloca o desenvolvimento da sensibilidade como primeira condição e particularmente necessária para "uma formação adequada que pressuponha um treino na arte de entender e esperar, um desenvolvimento no sentido da criação e da imaginação."

Retomando os escritos de Japiassu (1976), para precisar o sentido do termo "interdisciplinaridade", é necessário definir inicialmente o conceito de "disciplinaridade" que, segundo o autor, "significa uma progressiva exploração científica especializada numa certa área ou domínio homogêneo de estudo, termo mais empregado para designar o ensino de uma ciência" (Ibid., p. 72). Fazendo algumas precisões de ordem epistemológica nesses termos, chega-se a uma diferenciação dos diversos tipos ou modalidades do "interdisciplinar" ou "domínio interdisciplinar" a partir do qual discute conceitos vizinhos.

1. Multidisciplinaridade: Gama de disciplinas que propõe-se simultaneamente, mas, sem fazer aparecer as relações que possam existir entre elas; [destina-se a um] sistema de um só nível e de objetivos múltiplos; [mas] sem nenhuma cooperação.

2. Pluridisciplinaridade: Justaposição de diversas disciplinas, situadas geralmente no mesmo nível hierárquico e agrupadas de modo a fazer aparecer as relações existentes entre elas; [destina-se a um] sistema de um só nivel e de objetivos múltiplos; [no qual] há cooperação, mas sem coordenação.

3. Interdisciplinaridade: Axiomática comum a um grupo de disciplinas conexas e definida no nível hierárquico imediatamente superior, o que introduz a noção de finalidade; [destina-se a um] sistema de dois niveis e de objetivos múltiplos [no qual há] coordenação procedendo do nivel superior.

4. Transdisciplinaridade: Coordenação de todas as disciplinas e interdisciplinas do sistema de ensino inovado, sobre a base de uma axiomática geral; [destina-se a um] sistema de niveis e objetivos múltiplos; [há] coordenação com vistas a uma finalidade comum dos sistemas (JANTSCH, 1972 apud JAPIASSU, 1976, p. 73-74).

Acompanhando as ideias de Japiassu (1976), Pombo (2008) propõe pensar a interdisciplinaridade em termos de níveis ou gradações: pluri/multi/inter/trans (disciplinares). Tendo em vista a dificuldade de determinar exatamente a fronteira a partir da qual uma determinada prática se encaixa num determinado nível, Pombo (2004, p. 31) sugere que essas gradações formam um continuum, conforme esquematizado na Fig. 1. Esse continuum vai do paralelismo: presente na pluri/multi (disciplinaridade), que implica pôr as disciplinas em paralelo em torno de alguma ideia similar, estabelecendo possíveis coordenações sem promover a dialogicidade ou planejamento em conjunto; passando por um nível de 
convergência: caracterizado pela combinação de disciplinas, onde estaria situada a interdisciplinaridade e que implicaria de acordo com Pombo (2004) a necessidade de interação dialógica e comunicativa entre os agentes educativos; até chegar no nível da transdisciplinaridade: caracterizada pela unificação (fusão) de conhecimentos que transcendem as fronteiras disciplinares.

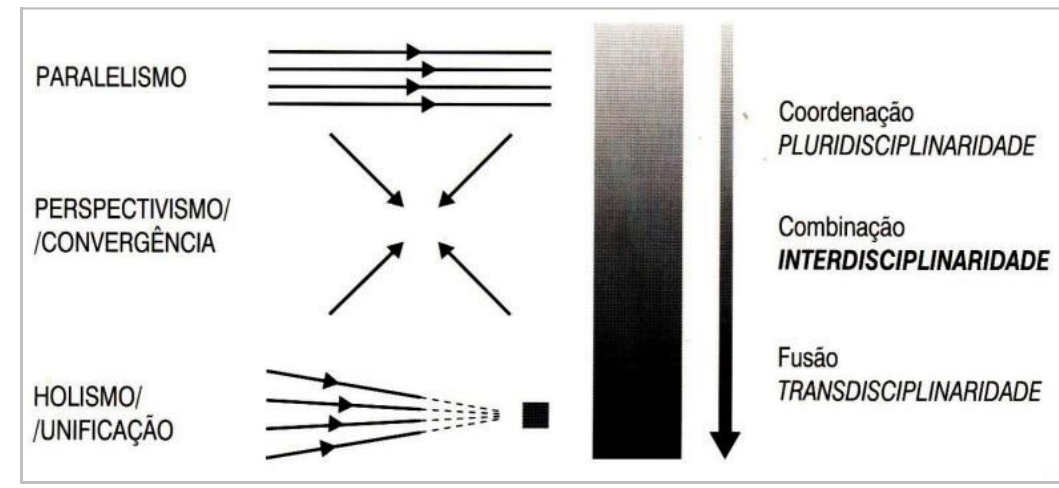

Fig. 1 - Gradações (pluri/multi/inter/trans) disciplinaridade.

Fonte: Pombo (2008, p. 6).

A título de exemplo de pluridisciplinaridade, podemos destacar os temas transversais, propostos nos Parâmetros Curriculares Nacionais/Temas Transversais abordados em todas as disciplinas.

O termo transdisciplinaridade, originalmente criado por Jean Piaget, e divulgado, pela primeira vez, no I Seminário Internacional sobre pluridisciplinaridade e interdisciplinaridade, realizado na Universidade de Nice, em 1970, completa a gradação esboçada às terminações anteriores e a caracteriza como uma etapa previsível das associações, mais do que uma possibilidade real.

Adotando a interdisciplinaridade como um processo e uma visão de mundo que compreende aspectos epistemológicos da prática docente, que se manifesta também na ação responsável na sociedade, Klein (1990, p. 188-189 apud SANTOMÉ, 1998, p. 65) sugere alguns passos que costumam estar presentes em qualquer intervenção interdisciplinar, que devem ser seguidos com flexibilidade e não como uma linha rígida e linear de ação:

1. a) Definir o problema (interrogação, tópico, questão).

b) Determinar os conhecimentos necessários, inclusive as disciplinas representativas e com necessidade de consulta, bem como os modelos mais relevantes, tradições e bibliografia.

c) Desenvolver um marco integrador e as questões a serem pesquisadas.

2. a) Especificar os estudos ou pesquisas concretas que devem ser empreendidos.

b) Reunir todos os conhecimentos atuais e buscar nova informação.

c) Resolver os conflitos entre as diferentes disciplinas implicadas, tratando de trabalhar com um vocabulário comum e em equipe. 
d) Construir e manter a comunicação através de técnicas integradoras (encontros e intercâmbios e interações frequentes, etc.).

3. a) Comparar todas as contribuições e avaliar sua adequação, relevância e adaptabilidade.

b) Integrar os dados obtidos individualmente para determinar um modelo coerente $e$ relevante.

c) Ratificar ou não a solução ou resposta oferecida.

d) Decidir sobre o futuro da tarefa, bem como sobre a equipe de trabalho.

A concepção de interdisciplinaridade apresentada e defendida por Santomé (1998) traz no seu âmago vantagens como: uma intervenção educativa mais aberta, dialógica, que propicia o exercício do protagonismo, tanto no ato de aprender como no ato de ensinar, uma maior abertura do canal de comunicação entre os atores sociais que constroem o cenário curricular, maior possibilidade de trabalho, análise e interpretação dos conteúdos culturais.

Destacam-se, ao final dessa fundamentação, como ponto comum entre os autores, a necessidade do exercício prático consciente da base teórica como um processo consistente de contraposição ao sistema atual. Apresentam, também em consonância, o objetivo de resgatar a percepção da totalidade perdida quanto ao conhecimento.

Como pontos divergentes podemos citar que autores como Japiassu e Fazenda lançam-se a partir dos compartimentos procurando remendar os pedaços que praticamente já não dialogam entre si, enquanto que Jantsch e Bianchetti não aceitam a ideia de que o somatório de individualidades ou de sujeitos pensantes possam apreender a complexidade do problema/objeto e Morin parte da concepção da igualdade das características entre o todo e as partes e prenuncia as medidas que devem ser tomadas para superar as lacunas deixadas pela visão cartesiana que atualmente se impõe.

Enquanto Japiassu (1976), Fazenda (2012, 2013, 2014) e Jantsch e Bianchetti (2011) abordam sobre disciplina e apontam a interdisciplinaridade como recurso válido para superação da mencionada divisão cartesiana; Morin (2011), que sequer utiliza o termo interdisciplinaridade, apresenta o pensamento complexo como melhor opção para superar a crise da superespecialização.

A partir das diversas definições de interdisciplinaridade, algumas inclusive antagônicas, bem como as características e pressupostos desse nível de relação, neste trabalho, entendemos interdisciplinaridade como

[...] qualquer forma de combinação entre duas ou mais disciplinas com vista à compreensão de um objeto a partir da confluência de pontos de vista diferentes. A interdisciplinaridade implica, portanto, alguma reorganização do processo de ensino/aprendizagem e supõe um trabalho continuado de colaboração dos professores envolvidos (POMBO, 1993, p. 13).

Assumimos também as ideias de Japiassu (1976) sobre a essência da interdisciplinaridade que incorpora os resultados de várias disciplinas, tomando-lhes de 
empréstimo, esquemas conceituais e que a interdisciplinaridade não pode ser apenas estudada, mas exercida.

Assim sendo, destacam-se, ao final dessa breve fundamentação, alguns pontos de convergência entre os autores, nos quais a análise dos dados da pesquisa descrita neste manuscrito buscou se alicerçar:

$\Rightarrow$ a prática docente necessita incorporar os pressupostos teóricos sobre a interdisciplinaridade, contrapondo-se ao sistema atual de ensino marcado pela excessiva fragmentação.

$\Rightarrow \quad$ o objetivo da interdisciplinaridade concentra-se em resgatar a percepção da totalidade perdida quanto ao conhecimento.

$\Rightarrow \quad$ alerta-se para o exagero da compartimentalização do conhecimento, reduzindoo apenas a um objeto visto em partes que o constituem, sem se preocupar com a conjunção harmoniosa e a dimensão subjetiva da sua totalidade.

O que se observa, no âmbito da interdisciplinaridade, é que há um distanciamento entre o discurso e a prática. Há a necessidade, pois, de se fazer esta transposição do discurso para a ação. Neste sentido, é válido destacar que os saberes disciplinares, os conteúdos, a "matéria" ensinada em cada disciplina, por si só, não é suficiente. Compreender a verdadeira missão da educação é, talvez, a saída para superar a excessiva fragmentação disciplinar em prol de uma visão mais abrangente e transcendente.

\section{Percurso metodológico}

Com a finalidade de responder à problemática principal, realizamos uma revisão sistemática da literatura, investigando, em periódicos nacionais de divulgação de pesquisas em ensino de Ciências e de Física, ações de caráter interdisciplinar propostas e implementadas, no âmbito da Educação Básica, por professores de Ciência e de Física, contemplando campos conceituais da Física, ou situações-problema e objetos de estudo que demandem conhecimento de conceitos físicos.

Os trabalhos de revisão são definidos, por Noronha e Ferreira (2000, p. 191), como:

[...] estudos que analisam a produção bibliográfica em determinada área temática, dentro de um recorte de tempo, fornecendo uma visão geral ou um relatório do estado da arte sobre um tópico específico, evidenciando novas ideias, métodos, subtemas que têm recebido maior ou menor ênfase na literatura selecionada.

A escolha dos periódicos buscou contemplar periódicos especializados em Ensino e/ou Educação em Ciências e/ou Física, de abrangência nacional, classificados com Qualis A1 e A2 de acordo com a avaliação da CAPES na área do Ensino, apresentados na Tabela 1. 
Tabela 1 - Lista de Periódicos pesquisados.

\begin{tabular}{|l|l|l|}
\hline $\begin{array}{l}\text { QUALIS } \\
\text { CAPES }\end{array}$ & \multicolumn{1}{|c|}{ PERIÓDICO } & ABREVIATURA $^{6}$ \\
\hline A1 & Ciência \& Educação & Cie\&Edu \\
\hline A1 & Ensaio Pesquisa em Educação em Ciências & Ensaio \\
\hline A1 & Revista Brasileira de Ensino de Física & RBEF \\
\hline A2 & $\begin{array}{l}\text { Acta Scientiae: Revista de Ensino de Ciências e } \\
\text { Matemáticas }\end{array}$ & Acta Scientiae \\
\hline A2 & Acta Scientiarum Education & Acta Scientiarum \\
\hline A2 & $\begin{array}{l}\text { Alexandria: Revista de Educação em Ciência e } \\
\text { Tecnologia }\end{array}$ & Alexandria \\
\hline A2 & $\begin{array}{l}\text { Amazônia: Revista de Educação em Ciências e e } \\
\text { Matemáticas }\end{array}$ & Amazônia \\
\hline A2 & Areté: Revista Amazônica de Ensino de Ciências & Areté \\
\hline A2 & Caderno Brasileiro de Ensino de Física & CBEF \\
\hline A2 & Investigações em Ensino de Ciências & IENCI \\
\hline A2 & Revista Brasileira de Ensino de Ciência e Tecnologia & RBECT \\
\hline A2 & $\begin{array}{l}\text { Revista Brasileira de Pesquisa em Educação em } \\
\text { Ciências }\end{array}$ & RBPEC \\
\hline A2 & Revista de Educação, Ciência e Matemática & RECM \\
\hline A2 & Revista de Ensino de Ciências e Matemática & REnCiMa \\
\hline A2 & Revista Práxis & Práxix \\
\hline A2 & Revista Vidya & Vidya \\
\hline
\end{tabular}

Fonte: elaborado pelos autores.

A busca de trabalhos nos periódicos compreendeu as publicações ocorridas no período entre 2006 a 2018 e para tal, foram utilizados os sites oficiais e a biblioteca eletrônica Scielo (Scientific Eletronic Library). Com o objetivo de, inicialmente, selecionar trabalhos que apresentassem os termos e conceitos mais evidenciados, tanto na problemática da pesquisa como na fundamentação teórica, utilizamos como conceitos de busca os descritores: relações disciplinares, integração de disciplinas, disciplinar como raiz dos conceitos de interdisciplinar, multidisciplinar, pluridisciplinar e transdisciplinar e suas derivadas; verificados no título, resumo e palavras-chave. Vários periódicos não dispunham de ferramenta específica para busca e, portanto, foram analisados os respectivos índices, inicialmente em relação ao título do trabalho, seguido das palavras chaves e finalmente do resumo do trabalho.

\footnotetext{
${ }^{6}$ No decorrer do trabalho, serão utilizadas as abreviaturas para referir-se aos periódicos.
} 
A busca sistemática por artigos envolvendo os descritores acima apresentados, resultou em 401 artigos. Para identificar os artigos alinhados ao objetivo dessa pesquisa realizou-se a leitura criteriosa dos resumos dos artigos inicialmente selecionados.

Como alguns periódicos foram selecionados a partir de uma busca manual, optamos por manter alguns artigos que, embora não apresentassem os descritores adotados, estavam fortemente alinhados ao tema da pesquisa.

Em uma triagem inicial alguns artigos foram excluídos, adotando-se os seguintes critérios: i) não direcionados à educação básica ou formação de professores ou que se afastam muito do contexto de interesse da pesquisa: a título de exemplificação, citamos o artigo de Souza et. al (2018) que apresenta uma abordagem interdisciplinar para operacionalização de uma disciplina integradora no currículo médico; e ii) os trabalhos apenas tangenciam ou abordam circunstancialmente o tema da presente revisão, apresentados apenas para justificar aspectos legais ou associados a diretrizes educacionais.

Aplicando-se esses critérios, 212 artigos foram excluídos, restando ainda, 189 artigos para categorização e análise interpretativa. Salientamos que esse procedimento adotado, para seleção dos artigos, tem o potencial de fornecer exclusivamente um panorama das relações disciplinares presentes na área das Ciências da Natureza e, especialmente no Ensino de Física.

Como primeira etapa, analisou-se o ano de publicação dos trabalhos inicialmente selecionados, a fim de verificar a incidência temporal dessa temática.

Em seguida, com o objetivo de filtrar os trabalhos que contemplavam as especificidades do problema foco dessa pesquisa, selecionando artigos que relacionavam conceitos da Física com outras áreas do conhecimento, os artigos foram distribuídos em dois grupos, definidos a priori, separando trabalhos que apresentaram relações disciplinares entre conceitos da área de Ciências e outras áreas, contemplando especialmente conceitos da Física de Trabalhos que apresentaram relações disciplinares contemplando conceitos específicos de outras áreas (excluindo-se a Física).

Alguns trabalhos, apesar de não tratarem das relações disciplinares entre conceitos da Física e de outros componentes curriculares, foram selecionados em função da sua abrangência geral sobre a temática, aprofundamento teórico ou por contemplar temáticas de Ensino de Ciências com potenciais para integrar o Ensino de Física.

É importante ressaltar que nessa etapa consideraram-se apenas as informações prestadas pelos autores de cada trabalho, sem analisar o caráter e a efetivação da relação disciplinar proposta.

Tendo em vista que o objetivo dessa pesquisa busca identificar de que forma o Ensino de Física tem se articulado com outras áreas do conhecimento, os trabalhos distribuídos no segundo grupo não serão objeto de categorização e análise e, portanto, não serão apresentados nas referências ao final desse trabalho.

$\mathrm{Na}$ perspectiva de analisar as características dos estudos, focos de abordagem e objetivos dos artigos classificados no grupo 1, empregou-se a categorização temática segundo 
Bardin (2011, p. 135) que, consiste na descoberta de unidades de significação contempladas em uma "comunicação e cuja presença, ou frequência de aparição, podem significar alguma coisa para o objetivo analítico escolhido".

A partir desse processo de agrupar informações, emergiram novas categorias temáticas, que serão detalhados através do processo de inferência e interpretação das categorias emergentes da análise realizada.

É importante ressaltar que algumas categorias mantêm a característica de não serem mutuamente exclusivas, havendo artigos que podem se enquadrar em mais de uma categoria.

\section{Resultados e discussões}

Com o objetivo de verificar a incidência temporal das publicações selecionadas, essas foram distribuídas na Tabela 2, de acordo com o ano de publicação.

Tabela 2 - Artigos selecionados por periódico e ano de publicação.

\begin{tabular}{|c|c|c|c|c|c|c|c|c|c|c|c|c|c|c|c|}
\hline $\begin{array}{l}\text { Anos } \\
\text { Periódicos }\end{array}$ & ஓ્ণ & હે̊) & $\stackrel{\infty}{\stackrel{\overbrace{}}{े}}$ & ஓ् & 를 & $\overline{\bar{N}}$ & 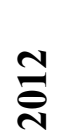 & $\stackrel{m}{\stackrel{\sim}{\nu}}$ & $\underset{\sim}{\stackrel{\sim}{~}}$ & $\stackrel{n}{\stackrel{n}{\sim}}$ & 록 & 록 & $\stackrel{\infty}{\stackrel{\sim}{\hat{~}}}$ & تే & $e^{\circ}$ \\
\hline Cie\&Edu & 0 & 2 & 2 & 2 & 1 & 1 & 1 & 1 & 3 & 2 & 1 & 2 & 2 & 20 & $11 \%$ \\
\hline Ensaio & 2 & 0 & 0 & 1 & 1 & 0 & 3 & 0 & 2 & 3 & 1 & 1 & 1 & 15 & $8 \%$ \\
\hline RBEF & 0 & 2 & 1 & 0 & 1 & 0 & 1 & 0 & 2 & 0 & 1 & 4 & 0 & 12 & $6 \%$ \\
\hline Acta Scientiae & 1 & 1 & 0 & 0 & 0 & 0 & 1 & 0 & 1 & 0 & 5 & 0 & 0 & 9 & $5 \%$ \\
\hline Acta Scientiarum & 0 & 0 & 0 & 0 & 0 & 0 & 0 & 0 & 0 & 0 & 1 & 1 & 2 & 4 & $2 \%$ \\
\hline Alexandria & 0 & 0 & 0 & 0 & 1 & 1 & 3 & 2 & 1 & 1 & 2 & 0 & 0 & 11 & $6 \%$ \\
\hline Amazônia & 0 & 1 & 0 & 0 & 1 & 0 & 0 & 1 & 0 & 0 & 2 & 0 & 1 & 6 & $3 \%$ \\
\hline Areté & 0 & 0 & 0 & 0 & 1 & 1 & 2 & 3 & 8 & 5 & 2 & 0 & 1 & 23 & $12 \%$ \\
\hline CBEF & 0 & 1 & 1 & 1 & 1 & 0 & 2 & 1 & 2 & 4 & 1 & 0 & 1 & 15 & $8 \%$ \\
\hline IENCI & 1 & 2 & 3 & 0 & 0 & 1 & 3 & 1 & 2 & 1 & 0 & 3 & 1 & 18 & $10 \%$ \\
\hline RBECT & 0 & 0 & 2 & 0 & 0 & 0 & 0 & 0 & 0 & 0 & 2 & 7 & 3 & 14 & $7 \%$ \\
\hline RBPEC & 0 & 3 & 0 & 1 & 0 & 4 & 2 & 1 & 1 & 0 & 1 & 1 & 0 & 14 & $7 \%$ \\
\hline RECM & 0 & 0 & 0 & 0 & 0 & 0 & 0 & 0 & 0 & 0 & 1 & 0 & 6 & 7 & $4 \%$ \\
\hline REnCiMa & 0 & 0 & 0 & 0 & 0 & 0 & 1 & 0 & 0 & 1 & 1 & 1 & 4 & 8 & $4 \%$ \\
\hline Práxix & 0 & 0 & 0 & 0 & 1 & 2 & 1 & 1 & 0 & 1 & 1 & 1 & 0 & 8 & $4 \%$ \\
\hline Vidya & 0 & 0 & 0 & 0 & 0 & 1 & 1 & 0 & 1 & 0 & 0 & 1 & 1 & 5 & $3 \%$ \\
\hline TOTAL & 4 & 13 & 9 & 5 & 8 & 11 & 21 & 11 & 23 & 18 & 22 & 22 & 23 & 189 & $\%$ \\
\hline
\end{tabular}

Fonte: elaborado pelos autores. 
Conforme é possível observar na Tabela 2, a maioria dos periódicos apresenta em torno de uma ou duas publicações sobre o tema, por ano. $\mathrm{O}$ aspecto temporal das publicações, pode ser melhor visualizado através do gráfico da Fig. 2.

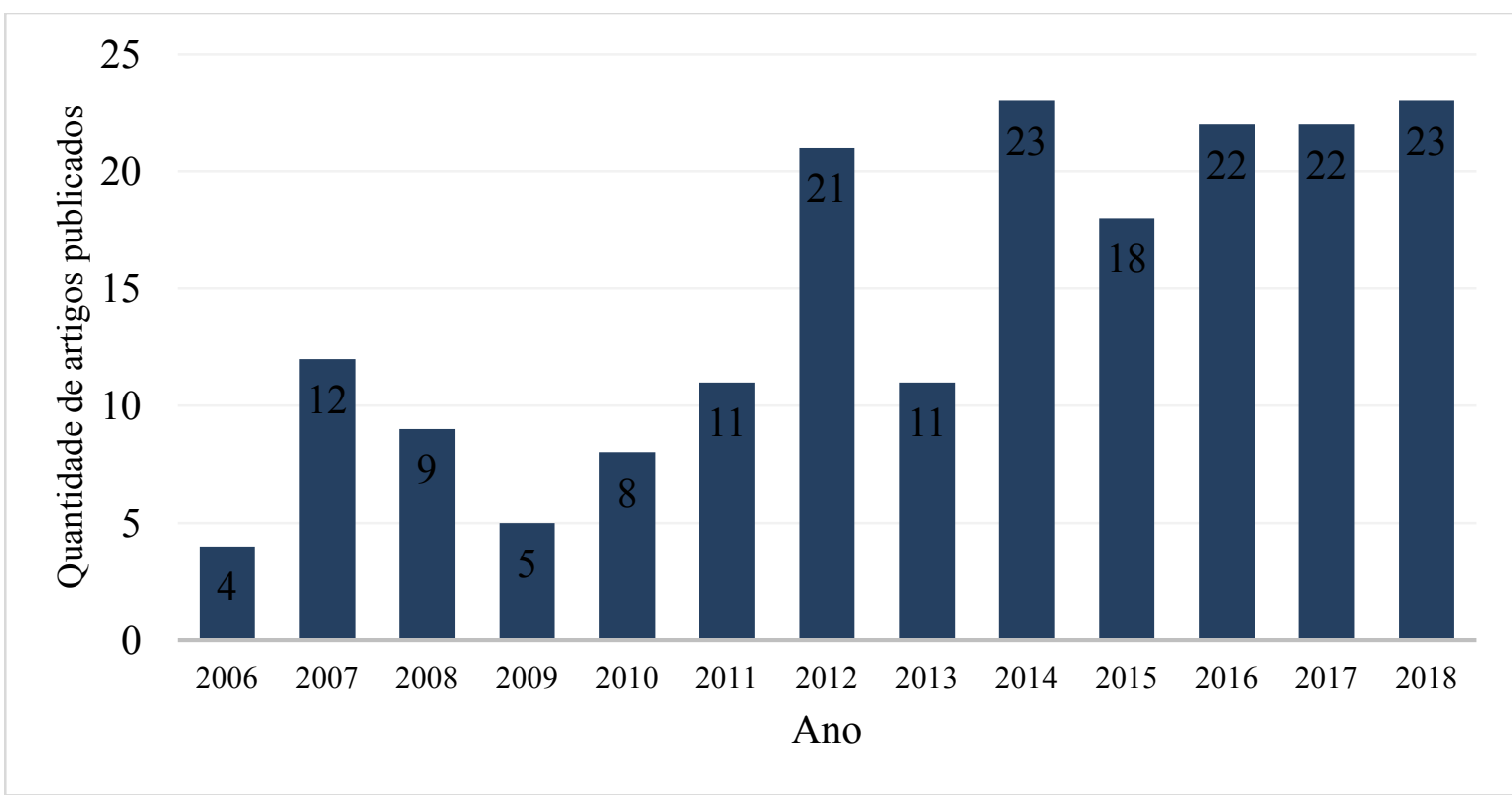

Fig. 2 - Quantidade de artigos por ano de publicação.

Fonte: elaborado pelos autores.

Pelo gráfico apresentado, verifica-se um aumento significativo das publicações contemplando a temática pesquisada. Em alguns periódicos observou-se, inclusive, a inclusão de volumes contemplando especificamente a temática da interdisciplinaridade, o que justifica parcialmente o crescimento no número de publicações nos últimos anos.

É possível verificar, na distribuição percentual dos artigos por periódicos (Tabela 2), que os que mais publicaram artigos contemplando relações disciplinares foram Areté, Cie\&Edu e IENCI, concentrando 33\% do total das publicações.

Tabela 3 - Distribuição dos trabalhos divididos de acordo com critério definido à priori.

\begin{tabular}{llc}
\hline Grupo 1 & $\begin{array}{l}\text { Trabalhos que apresentaram relações disciplinares entre conceitos da } \\
\text { área de Ciências e outras áreas, contemplando especialmente }\end{array}$ & \\
& conceitos da Física. & \\
\hline Grupo 2 & $\begin{array}{l}\text { Trabalhos que apresentaram relações disciplinares contemplando } \\
\text { conceitos específicos de outras áreas (excluindo-se a Física) }\end{array}$ & \\
\hline
\end{tabular}

Fonte: elaborado pelos autores.

Com o objetivo de responder o problema de pesquisa proposto "Como o Ensino de Física tem se articulado com outras áreas do conhecimento, na Educação Básica, na proposição de ações interdisciplinares ou em outros níveis de relações disciplinares?” foram 
destacados, conforme apresentado na Tabela 4, apenas os trabalhos que contemplaram a Física como componente curricular na perspectiva das relações disciplinares em conjunto com outros componentes e/ou áreas do conhecimento.

Apesar de alguns trabalhos selecionados não apresentarem propostas de caráter interdisciplinar, de acordo com a perspectiva e referenciais teóricos dessa pesquisa, mantiveram-se na relação de análise, devido à utilização das relações disciplinares pelos seus autores.

Como os periódicos escolhidos para essa revisão são específicos da área de Ensino de Ciência e de Física, é possível observar um número significativo de trabalhos que tratam das relações disciplinaridade entre a Física e outras áreas do conhecimento. A partir da leitura detalhada das 107 produções acadêmicas classificadas no grupo 1, procedeu-se a exploração e transformação desse material por padronização e equivalência, ou seja, pela codificação, tratamento dos dados brutos, recortes, determinação das unidades de significado e categorização.

Desse processo, de determinação de unidades de significados, emergiram categorias: i) abordagem da natureza e objetivos das pesquisas, que serão detalhados através do processo de inferência e interpretação das categorias emergentes da análise realizada; ii) de acordo com os níveis das relações disciplinares que serão classificadas de acordo com a definição dos autores dos trabalhos sem a análise sob o ponto de vista dessa pesquisa.

\section{i) Categorização dos trabalhos quanto à abordagem, natureza e objetivos das pesquisas}

Através do processo de inferência e interpretação das categorias emergentes, os trabalhos foram agrupados em 4 categorias, conforme Tabela 4 . O critério utilizado para essa categorização foi a equivalência entre os trabalhos em relação a abordagem, à natureza e aos objetivos da pesquisa.

Em relação à categoria 1, podemos destacar as relações estabelecidas entre saberes de duas disciplinas do núcleo comum, por exemplo, entre Física e Biologia (DORTA; SOUZA; MURAMATSU, 2016; MELO JÚNIOR, 2015; VILLANI; FRANZONI; VALADARES, 2008), Física e Matemática (BATISTA; LAVAQUI; SALVI, 2008), Física e Artes (ANDRADE; NASCIMENTO; GERMANO, 2007; MEDINA; BRAGA, 2010), Física e Química (ROCHA FILHO et al., 2009, MONTEIRO et al., 2012; 2013; 2015), Física e História (GODOI; FIGUEIRÔA, 2008) ou entre três ou mais disciplinas como Física, Química e Biologia (PIMENTEL et al., 2014; REGIANI et al., 2012; BOFF; PANSERADE-ARAUJO, 2011) e Física, Biologia, Matemática e Química (RICARDO; ZYLBERSZTAJN, 2007). 
Tabela 4 - Categorização dos trabalhos quanto à abordagem, natureza e objetivos das pesquisas.

\begin{tabular}{|l|l|r|}
\hline \multicolumn{1}{|c|}{ Categorias } & Trabalhos \\
\hline Categoria 1 & $\begin{array}{l}\text { Trabalhos que apresentaram propostas de atividades de ensino } \\
\text { implementadas ou não, estabelecendo relações disciplinares } \\
\text { entre os conceitos da Física/Ciência e outros componentes } \\
\text { curriculares e/ou áreas de conhecimento sem a utilização de } \\
\text { uma metodologia ou abordagem temática específica. }\end{array}$ & $\mathbf{3 0}$ \\
\hline Categoria 2 & $\begin{array}{l}\text { Trabalhos que contemplaram estudos e pesquisas de natureza } \\
\text { teórica, pressupostos legais, presença e importância da } \\
\text { temática na organização curricular e na formação de } \\
\text { professores, bem como concepções de pesquisadores e } \\
\text { professores sobre o tema e possibilidade e dificuldades na sua } \\
\text { implementação. }\end{array}$ & \\
\hline Categoria 3 & $\begin{array}{l}\text { Trabalhos que apresentaram propostas de atividade de ensino } \\
\text { de Física a partir de projetos e temas geradores, abordagem } \\
\text { temática CTS }{ }^{7}, \text { Situações de Estudo e Ilhas Interdisciplinares } \\
\text { de racionalidade (Fourez) e aplicações tecnológicas como } \\
\text { possibilidades para o ensino de conceitos físicos. }\end{array}$ & \\
\hline Categoria 4 & $\begin{array}{l}\text { Trabalhos que apresentaram conceitos da Física em aplicações } \\
\text { contextualizadas ou como ferramenta para outras áreas do } \\
\text { conhecimento. }\end{array}$ & $\mathbf{1 7}$ \\
\hline
\end{tabular}

Fonte: elaborado pelos autores.

A Física também se apresenta relacionada com outras disciplinas como, por exemplo, com a Música (COELHO; MACHADO, 2015; CAVALCANTE et al., 2012), com a Biomecânica e Anatomia (REZENDE; GARCIA; COLA, 2006), com a Fisiologia da Audição e Fonoaudiologia (BASTOS; MATTOS, 2009). Conceitos da Física também foram contemplados incluídos na área das Ciências Naturais como propostas sob uma perspectiva interdisciplinar com a área das Ciências Humanas em geral (HARTMANN; ZIMMERMANN, 2007).

A fim de descrever os trabalhos agrupados na categoria 2, como estudos e pesquisas de natureza teórica, pressupostos legais, organização curricular, formação de professores ou concepções de pesquisadores e professores sobre a temática, exploramos superficialmente os pressupostos teóricos utilizados. Trabalhos como Santos e Valeiras (2014), Roso e Auler (2016) aprofundaram a interdisciplinaridade presente nos currículos escolares. Os

${ }^{7}$ CTS: Sigla que significa Ciência, Tecnologia e Sociedade ou Estudos Sociais da Ciência e da Tecnologia, designada como uma abordagem ou um movimento social. (CHRISPINO et al., 2013) 
pressupostos da legislação nacional brasileira estiveram presentes em todos os trabalhos analisados nessa categoria, como podemos evidenciar, por exemplo, no trabalho de Ricardo e Zylbersztajn (2007).

De acordo com Abril e Nardi (2015) a interdisciplinaridade também foi destacada como um objeto de estudo da pesquisa em Ensino de Física no Brasil, tendo em vista tratar-se de um pressuposto para a aprendizagem.

Alguns trabalhos, apesar de citarem a relação entre disciplinas, ressaltam a importância da História da Ciência no Ensino de Física, o que na nossa visão representa mais uma questão filosófica e epistemológica de Ensino. Lucisano e Neves (2012) apresentam uma análise das perspectivas inter e transdisciplinares na História da Ciência presentes nos livros didáticos de Física. Cordeiro e Peduzzi (2014) destacam o potencial da história da ciência para a compreensão do poder do olhar disciplinar para um determinado objeto de pesquisa.

$\mathrm{Na}$ categoria 3, onde foram destacados trabalhos de naturezas interdisciplinares específicas, podemos destacar termos metodológicos como ilhas interdisciplinares para resolver uma situação-problema (REGIANI et al., 2012) ou ainda sugerindo situações de estudo, conforme Halmenschlager e Souza (2012) e Jesus e Guzzi Filho (2018), como possibilidade interdisciplinar. A interdisciplinaridade foi apresentada como uma metodologia presente nas situações de estudo, evidenciando inclusive a utilização de recursos como mapas conceituais e metaconceituais como instrumento de investigação (MALDANER; COSTABEBER; MACHADO, 2012).

Além das situações-problema, os experimentos didáticos são citados como recurso potencial para a efetivação da interdisciplinaridade conforme podemos observar nos trabalhos de Damasio e Steffani (2007), Dorta, Souza e Muramatsu (2016), Rocha Filho et al. (2009), Monteiro et al. (2012; 2015) e Boff e Pansera-de-Araújo (2011).

Fazenda (2002, 2012 e 2013), destaca que a interdisciplinaridade é um empreendimento que visa a proporcionar às disciplinas uma nova razão de existência - e não eliminá-las. Ela é um processo que torna possível a compreensão da realidade como um todo, constituída pela relação entre o mundo objetivo e o sujeito que, por sua vez, tenta captar o significado desse mundo de uma forma particular e subjetiva. A integração é apenas um momento do processo, que possibilita chegar a "novos questionamentos, novas buscas, para uma mudança na atitude de compreender e entender" (FAZENDA, 2002, p. 49), mas não a uma síntese disciplinar.

Dentro da categoria 3, foram verificados trabalhos que atendem a interdisciplinaridade sob uma abordagem temática (MUENCHEN; AULER 2007) e especificamente abordagem CTS, bem como, na perspectiva dos temas transversais, conforme destaca-se nas pesquisas de Damasio e Steffani (2007), Roehrig e Camargo (2014), Chrispino et al. (2013), e Roso et al. (2015). Entre as temáticas sugeridas estão a Educação Ambiental, Astronomia, Contaminações nucleares e aplicações tecnológicas (AMANTES; COELHO, 
2013). Temas geradores mais amplos como Energia, por exemplo, foram verificados em vários trabalhos conforme pode exemplificar Gomes e Garcia (2014), Boff e Pansera-deAraújo (2011), Rothberg e Quinato (2016), Morgado et al. (2016) e Wirzbicki e Zanon (2012). Alguns trabalhos que, apesar de apresentarem a interdisciplinaridade utilizando temas geradores e abordagem CTS, apenas discutem a sua importância sem evidenciar as características da área CTS. Corroborando com essa afirmação, Chrispino et al. (2013, p. 455) apontam que "os resultados permitem inferir que: [...] não é possível perceber a interdisciplinaridade e a contextualização características da área CTS".

$\mathrm{Na}$ categoria 4, foram distribuídos trabalhos que apresentaram a importância dos pressupostos de um componente curricular para resolver problemas de outro (CUNHA et al., 2012; NASSAR et al., 2008).

Sem utilizar necessariamente as gradações das relações disciplinares, mas evidenciando níveis de relação tratados com o termo "interação" entre Matemática e Física, foram encontrados trabalhos que utilizam situações problemas da Física para contextualizar dar sentido aos conceitos matemáticos como, por exemplo, do Cálculo (SANTAROSA; MOREIRA, 2011; SANTAROSA, 2013).

\section{ii) De acordo com os níveis das relações disciplinares}

A partir do agrupamento das informações, dando sequência à discussão das categorias emergentes, os trabalhos foram classificados (Tabela 5) em relação aos níveis das relações disciplinaridade (FAZENDA, 2012), respeitando a designação utilizada pelos autores de cada trabalho.

Tabela 5 - Níveis das relações disciplinares apresentados nos trabalhos.

\section{Relações disciplinares}

(Inter)disciplinaridade

(Multi)disciplinaridade

(Pluri)disciplinaridade

(Trans)disciplinaridade

\section{Quantidade de trabalhos}

88

10

2

8

Fonte: elaborado pelos autores.

$\mathrm{Na}$ distribuição acima apresentada, foram contempladas as gradações das relações disciplinares apresentadas na fundamentação deste trabalho. É possível verificar que o termo interdisciplinaridade está presente em 88 dos trabalhos analisados, sendo que em 79 desses trabalhos fora apresentado como único nível de relação. Do total dos trabalhos, apenas 7 apresentaram os níveis Multidisciplinaridade (4 trabalhos) e Transdisciplinaridade (3 trabalhos) de forma isolada.

Em contraposição ao resultado obtido, de acordo com os níveis de relações propostos por Pombo (2004), observa-se que quase a totalidade dos trabalhos agrupados quanto a 
abordagem, natureza e objetivos das pesquisas na Categoria 1 que contempla trabalhos que relacionam conceitos da física com outras áreas do conhecimento sem a utilização de uma metodologia interdisciplinar específica, ocorrem de forma paralela em torno de uma ideia similar, o que caracterizaria uma abordagem pluri ou multidisciplinar.

Tendo em vista a definição apresentada na fundamentação deste trabalho em relação aos níveis de relações disciplinares, verifica-se que muitos trabalhos estão classificados como interdisciplinares quando se utilizam de temas geradores, em que cada professor aborda o tema em sua disciplina, sob a perspectiva dessa. Em virtude desses trabalhos serem realizados sem qualquer relação com outras disciplinas, apresentam características mais próximas da multidisciplinaridade.

Em contraponto, entende-se que uma situação em que um professor, ao ensinar determinados conceitos, não se restringe apenas a apresentá-los sob o ponto de vista da sua disciplina, mas toma de empréstimo conhecimentos de outras áreas/disciplinas, atende mais efetivamente os pressupostos da interdisciplinaridade. Nesse sentido, defende-se que um trabalho em equipe não caracteriza necessariamente a interdisciplinaridade, enquanto trabalhos individuais que demonstram uma atitude de abertura frente ao novo conhecimento podem ser assim caracterizados.

É possível destacar os trabalhos que apresentaram abordagem metodológica específica baseada em Situações de Estudo, Ilhas Interdisciplinares de racionalidade e alguns de abordagem CTS, com características em nível de convergência, caracterizando a combinação de disciplinas e evidenciando o planejamento em conjunto e a dialogicidade. De acordo com as características apresentadas por Pombo (2004) trabalhos dessa natureza contemplam os pressupostos da interdisciplinaridade. Contudo, não é a natureza ou abordagem metodológica que garante essa convergência. Um fazer pedagógico e uma atitude de abertura frente ao objeto do conhecimento, está para além da natureza de abordagem em que se baseia a prática.

Durante a análise dos artigos, foi possível observar que vários deles apresentavam resultados de pesquisas com professores atuantes na educação básica e também com professores em formação inicial, investigando concepções de interdisciplinaridade (CARMINATTI; DEL PINO, 2015; DAL MOLIN et al., 2016; RAMOS; SILVA, 2018), verificações de sua aplicabilidade e os desafios e obstáculos que justificam a falta de efetivação (PIERSON; NEVES, 2011).

Colocar em prática a interdisciplinaridade não é tarefa fácil. Trabalhos como de Augusto e Caldeira (2007), Ozelame e Rocha Filho (2016) relatam dificuldades para a implementação de práticas interdisciplinares. As mesmas dificuldades também foram evidenciadas por Ávila et al. (2017) quais sejam: a falta de diálogo entre os professores, falta de planejamento e de tempo; os participantes da pesquisa enfatizaram também que a falta de diálogo entre os professores e coordenação pedagógica incentivava cada um a ensinar sua disciplina de forma fragmentada e desarticulada das demais. Sestari et al. (2020) destacam 
impasses apontados por professores de uma instituição federal como dificultadores para práticas interdisciplinares, entre eles podemos citar a falta de tempo de planejamento, a falta de um trabalho coletivo coordenado e que perpasse os currículos escolares, a fragmentação do conhecimento já instituída e arraigada nos espaços escolares e a formação dos professores baseada em especificidades. Esses apontamentos destacam a importância de uma formação continuada com foco nos pressupostos da interdisciplinaridade. Torna-se imprescindível possibilitar aos educadores o aprimoramento de seus saberes e estudos de referenciais teóricos e metodológicos que venham ao encontro das propostas e demandas atuais de Ensino, como a práxis, a contextualização e a interdisciplinaridade no Ensino de Ciências e de Física, por exemplo, num trabalho inconcluso e permanente, necessariamente coletivo.

Finalizando a discussão de resultados é importante destacar os especialistas teóricos mais citados nos trabalhos destacamos por ordem decrescente de citações Ivani Fazenda, Hilton Japiassu, Gérard Fourez, Edgar Morin, Yves Lenoir e Jurjo Santomé (MOZENA; OSTERMANN, 2014; 2016; HARTMANN; ZIMMERMANN, 2007; ROSO; AULER, 2016; BATISTA; SALVI, 2006). Outros especialistas e professores pesquisadores foram referenciados nos artigos selecionados, no entanto, não é objetivo dessa pesquisa listar todos eles.

Para corroborar com nossa pesquisa o artigo de Mozena e Ostermann (2014, p. 196) ressalta alguns teóricos da interdisciplinaridade,

\begin{abstract}
[...] São eles, por ordem de citações encontradas nas referências bibliográficas dos trabalhos revisados: Ivani Fazenda, Edgar Morin, Jurjo Santomé, Gerard Fourez, Yves Lenoir e Hilton Japiassu. Entre os artigos que tratam estritamente sobre fundamentos epistemológicos da interdisciplinaridade escolar, Fourez e Morin foram os mais citados.
\end{abstract}

Em relação aos referenciais de interdisciplinaridade utilizados nos artigos selecionados, é possível inferir que há predominância de autores nacionais como fonte de pesquisa dos trabalhos publicados nos principais periódicos.

\title{
V. Considerações finais
}

Tendo em vista a importância da interdisciplinaridade, no contexto educacional, este trabalho teve como objetivo discutir as definições do termo interdisciplinaridade apresentadas por autores de reconhecida experiência em pesquisa sobre a temática. Pressupostos e características das ações interdisciplinares também tiveram espaço neste trabalho.

Além da necessidade de destacar aspectos conceituais e metodológicos da interdisciplinaridade, este trabalho explorou através de uma pesquisa de revisão bibliográfica a questão principal: Como o Ensino de Física tem se articulado com outras áreas do conhecimento, na proposição de ações interdisciplinares ou em outros níveis de relações disciplinares? 
Concluído esse estudo de revisão bibliográfica, salienta-se, com amparo nos pressupostos teóricos defendidos pelos autores que deram aporte teórico a essa pesquisa, a necessidade de superação de um ensino fragmentado, linear e descontextualizado. A importância da interdisciplinaridade principalmente na Educação Básica, perpassa aspectos como o diálogo caracterizado como uma relação ou negociação entre um ou mais conhecimentos disciplinares escolares, não pertencentes apenas ao núcleo comum ou também chamadas disciplinas propedêuticas, mas também com outros saberes que talvez nem estejam caracterizados como disciplinas.

A falta de uma ideia clara do seu significado - e de como ela como pode acontecer são dois obstáculos a serem superados. Os professores têm uma multiplicidade de concepções sobre interdisciplinaridade, que vão desde a de que ela seja uma nova epistemologia, ou uma nova metodologia, até a de que ela constitui um instrumento para melhorar a aprendizagem (HARTMANN; ZIMMERMANN, 2006a apud HARTMANN; ZIMMERMANN, 2007).

Os resultados desta pesquisa evidenciaram uma quantidade significativa de trabalhos que apresentaram propostas de atividades de ensino implementadas ou não, que estabeleciam alguma relação entre conceitos da Física com outras áreas do conhecimento sem a utilização de uma abordagem metodológica específica. Paralelamente, observamos trabalhos de natureza teórica, atendendo aspectos legais e a presença do termo interdisciplinaridade na organização curricular e formação de professores, bem como concepções de pesquisadores e professores sobre o tema.

Um pequeno número de trabalhos, apenas 17, contemplou propostas baseadas em abordagens temáticas, a partir de projetos e temas geradores, abordagem CTS, Situações de Estudo e Ilhas Interdisciplinares de Racionalidade. Tendo em vista o potencial interdisciplinar caracterizado pela convergência entre as disciplinas, nesse tipo de abordagem, lamentamos que esse número seja tão reduzido, principalmente porque apenas a forma de abordagem não garante uma atitude interdisciplinar do docente que está implementando essas ações.

A presença da contextualização através de conceitos físicos também poderia ser mais significativa, tendo em vista que os pressupostos da contextualização e da interdisciplinaridade convergem em muitos aspectos.

Destaca-se também como potencial para atender os pressupostos da interdisciplinaridade, aquelas situações em que um professor não apresenta o objeto do conhecimento de forma fragmentada. Pelo contrário, apresenta determinados conceitos rompendo as fronteiras disciplinares, atendendo assim, a essência do conhecimento.

Evidencia-se nos resultados dessa análise, que em relação aos níveis ou gradações pluri/multi/inter/trans (disciplinares), a interdisciplinaridade é o mais utilizado pelos autores, presente em 88 dos trabalhos selecionados.

A interdisciplinaridade, na forma defendida pelos autores desse trabalho, a partir dos referenciais adotados, se apresenta para atender uma situação desencadeada de um conhecimento mais amplo que necessita dos saberes de várias áreas para dar conta de sua 
totalidade. No entanto, conclui-se que há um uso excessivo desse conceito e nem sempre adequado para determinadas situações. Observa-se também que a contextualização e a interdisciplinaridade, conceitos que ocorrem simultaneamente na maioria das práticas, não são aplicados com o aprofundamento teórico necessário (STADLER; HUSSEIN, 2017).

Apesar da importância da interdisciplinaridade como princípio pedagógico e norteador da atividade docente apresentada nas diretrizes educacionais nacionais e defendida por autores como Japiassu (1976) e Fazenda (2012, 2013, 2014), concluímos que a sua efetivação está longe de atingir de forma significativa o ambiente de sala de aula, especificamente situações de estudo que contemplem conceitos físicos. Entre algumas dificuldades relatadas pelos professores, a organização curricular fragmentada e as dificuldades para dialogar com os pares são algumas das justificativas para a não realização de ações interdisciplinares. Além de obstáculos epistemológicos, institucionais e metodológicos, ressaltam obstáculos em relação a sua própria formação específica, essencialmente disciplinar, como uma limitação para integrar saberes. Outros aspectos levantados apresentam uma visão funcionalista das disciplinas, necessárias apenas como ferramenta para instrumentalizar determinadas aplicações. Também, caso fosse atendida a necessidade de um planejamento de espaço e tempo, bem como uma previsão orçamentária adequada, teriam os obstáculos materiais transpostos o que também viabilizaria a necessária eliminação das barreiras entre as disciplinas e entre as pessoas que pretendem desenvolvê-la, oportunizando a supressão do monólogo e a instauração de uma prática dialógica (FAZENDA, 2014, p. 40-41).

Corroborando com essa pesquisa, Paviani (2008, p. 14) afirma que

O uso indiscriminado do termo no ensino, na pesquisa, no exercício profissional, nos meios de comunicação, em congressos e seminários, em subtítulos de obras científicas, aponta para múltiplos significados e, em consequência, para nenhum significado preciso aceito pela comunidade de professores e pesquisadores.

Além de destacar a importância da interdisciplinaridade para a compreensão do conhecimento amplo, que na sua forma real, não se apresenta fragmentado e compartimentalizado em "pedaços do saber" salienta-se a necessidade de partir da totalidade presente no cotidiano para efetivar o processo de ensino e aprendizagem. Como asserção de valor desse estudo, apresenta-se a necessidade de aprofundamento de pesquisas teóricas e práticas sobre o tema interdisciplinaridade na escola, dada a relevância dessa temática e a sua crescente utilização.

Conforme resultados dessa revisão, destacada como um dos obstáculos à efetivação da interdisciplinaridade, salientamos a necessidade de mudanças na formação inicial de professores, afinal, seria pelo menos ingênuo esperar que um professor que obteve toda a sua formação de forma fragmentada, possa efetivar sua docência contemplando plenamente os pressupostos da interdisciplinaridade. Essa afirmação não significa que os professores já em exercício não tenham condições de efetivar práticas interdisciplinares. Evidencia e corrobora, 
apenas, as dificuldades que esses professores têm em desenvolver a docência com esse foco e a necessidade da formação continuada em serviço que priorize a reflexão, dialogicidade, o estudo e planejamento tanto individual, como coletivo, bem como a importância de assumir a interdisciplinaridade como uma atitude de abertura frente ao objeto do conhecimento, incorporando os resultados de várias disciplinas.

\section{Agradecimentos}

Ao Instituto Federal de Educação, Ciência e Tecnologia do Rio Grande do Sul Campus Ibirubá.

\section{Referências}

ABRIL, O. L. C.; NARDI, R. Os "Objetos de Estudo" da pesquisa em ensino de Física segundo pesquisadores brasileiros. Revista Ensaio Pesquisa em Educação em Ciências, Belo Horizonte, v. 17, n. 2, p. 414-433, 2015.

AMANTES, A.; COELHO, G. Como a abordagem de ensino influencia a aprendizagem de conteúdos Científicos e Tecnológicos? Revista Brasileira de Pesquisa em Educação em Ciências, Belo Horizonte, v. 13, n. 1, p. 111-133, 2013.

AVILA, L. A. B. et al. A Interdisciplinaridade na Escola: Dificuldades e Desafios no Ensino de Ciências e Matemática. Revista Signos, v. 38, n. 1, p. 9-23, 2017.

ANDRADE, R. R. D. de; NASCIMENTO, R. S.; GERMANO; M. G. Influências da Física Moderna na obra de Salvador Dalí. Caderno Brasileiro de Ensino de Física, Florianópolis, v. 24, n. 3, p. 400-423, dez. 2007.

AUGUSTO, T. G. S.; CALDEIRA, A. M. A. Dificuldades para a implantação de práticas interdisciplinares em escolas estaduais apontadas por professores da área de Ciências da Natureza. Revista Investigações em Ensino de Ciências, Porto Alegre, v. 12, n. 1, p. 139154, 2007.

BARDIN, L. Análise de conteúdo. São Paulo: Edições 70, 2011.

BASTOS, P. W.; MATTOS, C. R. de. Física para uma saúde auditiva. Revista Brasileira de Pesquisa em Educação em Ciências, Belo Horizonte, v. 9, n. 3, 2009.

BATISTA, I. L.; LAVAQUI, V.; SALVI, R. F. Interdisciplinaridade escolar no ensino médio por meio de trabalho com projetos pedagógicos. Revista Investigações em Ensino de 
Ciências, Porto Alegre, v. 13, n. 2, p. 209-239, 2008.

BATISTA, I. L.; SALVI, R. F. Perspectiva pós-moderna e interdisciplinaridade educativa: pensamento complexo e reconciliação integrativa. Revista Ensaio Pesquisa em Educação em Ciências, Belo Horizonte, v. 8, n. 2, p. 147-160, dez. 2006.

BOFF, E. T. O.; PANSERA-DE-ARAÚJO, M. C. A Significação do conceito energia no contexto da situação de estudo alimentos: produção e consumo. Revista Brasileira de Pesquisa em Educação em Ciências, Belo Horizonte, v. 11, n. 3, p. 145-164, 2011.

BRASIL, MINISTÉRIO DA EDUCAÇÃO. Parâmetros Curriculares Nacionais. Secretaria de Educação Média e Tecnológica. Brasília, DF, 1998. Disponível em: $<$ http://portal.mec.gov.br/par/195-secretarias-112877938/seb-educacao-basica2007048997/12657-parametros-curriculares-nacionais-5o-a-8o-series $>$. Acesso em: out. 2020.

BRASIL, MINISTÉRIO DA EDUCAÇÃO. Parâmetros curriculares nacionais: ensino médio. Secretaria de Educação Média e Tecnológica. Brasília: MEC/SEFM, 1999.

BRASIL, Ministério da Educação. Diretrizes Curriculares Nacionais da Educação Básica. Secretaria de Educação Básica. Brasília, DF, 2013. Disponível em: $<$ http://portal.mec.gov.br/index.php?option=com_docman\&view=download\&alias=15548-dc-n-educacao-basica-nova-pdf\&Itemid=30192>. Acesso em: nov. 2020.

CARMINATTI, B.; DEL PINO, J. C. Concepções dos professores da área das Ciências da Natureza acerca da construção da interdisciplinaridade no Ensino Médio Politécnico: a contribuição dos saberes docente na realidade de duas escolas do norte gaúcho. Revista Investigações em Ensino de Ciências, Porto Alegre, v. 20, n. 2, p. 103-125, 2015.

CAVAlCANTE, J. C. L. et al. Física e Música: uma proposta interdisciplinar. Revista Areté: Revista Amazônica de Ensino de Ciências, Manaus, v. 5, n. 9, p. 101-111, ago.-dez. 2012.

CHRISPINO, A. et. al. A área CTS no Brasil vista como rede social: onde aprendemos? Revista Ciência \& Educação, Bauru, v. 19, n. 2, p. 455-479, 2013.

COELHO, S. M.; MACHADO, G. R. Acústica e música: uma abordagem metodológica para explorar sons emitidos por tubos sonoros. Caderno Brasileiro de Ensino de Física, Florianópolis, v. 32, n. 1, p. 207-222, abr. 2015. 
CORDEIRO, M. D.; PEDUZZI, L. O. Q. Entre os transurânicos e a fissão nuclear: um exemplo do papel da interdisciplinaridade em uma descoberta científica. Caderno Brasileiro de Ensino de Física, Florianópolis, v. 31, n. 3, p. 536-563, dez. 2014.

CUNHA, A. R. et al. Determinação de propriedades petrofísicas de rochas via simulação. Um caminho interdisciplinar. Revista Brasileira de Ensino de Física, São Paulo, v. 34, n. 4, 4315, dez. 2012.

DAL MOLIN, V. T. S. et al. Práticas interdisciplinares no Ensino médio integrado: concepções dos docentes das áreas técnicas e básicas. Revista Acta Scientiae, Canoas, v. 18, n. 3, p. 869-882, set.-dez. 2016.

DAMASIO, F.; STEFFANI, M. H. Ensinando física com consciência ecológica e com materiais descartáveis. Revista Brasileira de Ensino de Física, São Paulo, v. 29, n. 4, p. 593 597, dez. 2007.

DESCARTES, R. Discurso sobre o método. São Paulo: Hemus, 1978.

DORTA, M. P.; SOUZA, E. C. P.; MURAMATSU, M. O projetor de gotas e suas diversas abordagens interdisciplinares no Ensino de Física. Revista Brasileira de Ensino de Física, São Paulo, v. 38, n. 4, e4503, 2016.

FAZENDA, I. C. A. Integração e interdisciplinaridade no ensino brasileiro: efetividade ou ideologia? 5. ed. São Paulo: Edições Loyola, 2002.

FAZENDA, I. C. A. Integração e interdisciplinaridade no ensino brasileiro: efetividade ou ideologia? 6. ed. São Paulo: Edições Loyola, 2011a.

FAZENDA, I. C. A. Desafios e perspectivas do trabalho interdisciplinar no Ensino Fundamental: contribuições das pesquisas sobre interdisciplinaridade no Brasil: o reconhecimento de um percurso. Interdisciplinaridade. Revista do Grupo de Estudos e Pesquisa em Interdisciplinaridade, São Paulo, v. 1, n. 1, p. 10-23, out. 2011 b.

FAZENDA, I. C. A. Interdisciplinaridade: história, teoria e pesquisa. 18. ed. Campinas: Papirus, 2012.

FAZENDA, I. C. A. (Org.) O que é interdisciplinaridade? 2. ed. São Paulo: Cortez, 2013. FAZENDA, I. C. A. Interdisciplinaridade: um projeto em parceria. 7. ed. São Paulo: 
Edições Loyola, 2014.

GODOI, L. C. O. ; FIGUEIRÔA, S. F. M. Dois pesos e duas medidas: uma proposta para discutir a natureza do sistema de unidades de medidas na sala de aula. Caderno Brasileiro de Ensino de Física, Florianópolis, v. 25, n. 3, p. 523-545, dez. 2008.

GOMES, A. T.; GARCIA, I. K. Aprendizagem significativa na EJA: uma análise da evolução conceitual a partir de uma intervenção didática com a temática Energia. Revista Investigações em Ensino de Ciências, Porto Alegre, v. 19, n. 2, p. 289-321, 2014.

HALMENSCHLAGER, K. R.; SOUZA, C. A. Abordagem temática: uma análise dos aspectos que orientam a escolha de temas na situação de estudo. Revista Investigações em Ensino de Ciências, Porto Alegre, v. 17, n. 2, p. 367-384, 2012.

HARTMANN, A. M.; ZIMMERMANN, E. O trabalho interdisciplinar no Ensino Médio: a reaproximação das "Duas Culturas". Revista Brasileira de Pesquisa em Educação em Ciências, Belo Horizonte, v. 7, n. 2, 2007.

JANTSCH, A. P.; BIANCHETTI, L. Interdisciplinaridade: para além da filosofia do sujeito. In. JANTSCH, A. P.; BIANCHETTI, L. (Orgs.) Interdisciplinaridade: para além da filosofia do sujeito. 9. ed. atualizada e ampliada. Petrópolis: Vozes, 2011.

JAPIASSU, H. Interdisciplinaridade e patologia do saber. Rio de Janeiro: Imago Editora Ltda, 1976.

JESUS, D. de; GUZZI FILHO, N. J. de. O café nosso de cada dia: investigação da influência de uma situação de estudo no processo de ensino aprendizagem de Ciências da Natureza no ensino médio. Revista Brasileira de Ensino de Ciência e Tecnologia, Ponta Grossa, v. 11, n. 1, p. 108-132, jan.-abr. 2018.

LUCISANO, F. R.; NEVES, M. C. D. Uma análise das perspectivas inter e transdisciplinares na história da ciência presentes nos livros didáticos de física. Revista Práxis, Volta Redonda, v. 4, n. 8, ago. 2012.

MALDANER, O. A.; COSTA-BEBER, L. B.; MACHADO, A. R. Desenvolvimento e Aprendizagem de conceitos Biofísicoquímicos em uma Situação de Estudo: mapa conceitual e metaconceitual como instrumento de investigação. Alexandria Revista de Educação em Ciência e Tecnologia, Florianópolis, v. 5, n. 1, p. 85-111, maio 2012.

MEDINA, M.; BRAGA, M. O teatro como ferramenta de aprendizagem da Física e de 
problematização da natureza da Ciência. Caderno Brasileiro de Ensino de Física, Florianópolis, v. 27, n. 2, p. 313-333, ago. 2010.

MELO JÚNIOR, R. P. Qual é a influência da cor da luz na fotossíntese? Caderno Brasileiro de Ensino de Física, Florianópolis, v. 32, n. 1, p. 287-290, abr. 2015.

MONTEIRO, M. A. A. et al. Determinação do teor alcoólico da cachaça: uma discussão sobre o conceito de tensão superficial em uma perspectiva interdisciplinar. Caderno Brasileiro de Ensino de Física, Florianópolis, v. 29, n. 2, p. 229-245, ago. 2012.

MONTEIRO, M. A. A. et al. Determinação de sacarose no xarope artificial de groselha por medidas de viscosidade: uma abordagem interdisciplinar. Caderno Brasileiro de Ensino de Física, Florianópolis, v. 30, n. 3, p. 566-578, dez. 2013.

MONTEIRO, M. A. A. et al. Determinação da concentração de ácido acético no vinagre por medidas de tensão superficial: uma atividade didática interdisciplinar com vistas à mediação semiótica. Caderno Brasileiro de Ensino de Física, Florianópolis, v. 32, n. 1, p. 253-262, abr. 2015.

MORGADO, S. et al. Ensino orientado para a aprendizagem baseada na resolução de problemas e ensino tradicional: um estudo centrado em "transformação de matéria e energia". Revista Ensaio Pesquisa em Educação em Ciências, Belo Horizonte, v. 18, n. 2, p. 73-97, maio.-ago. 2016.

MORIN, E. Educação e complexidade: os sete saberes e outros ensaios. São Paulo: Cortez, 2002.

MORIN, E. Os sete saberes necessários à educação do futuro. 2. ed. rev. São Paulo: Cortez; Brasília: UNESCO, 2011.

MOZENA, E. R.; OSTERMANN, F. Uma revisão bibliográfica sobre a interdisciplinaridade no ensino das ciências da natureza. Revista Ensaio Pesquisa em Educação em Ciências, Belo Horizonte, v.16, n. 02, p. 185-206, maio-ago, 2014.

MOZENA, E. R.; OSTERMANN, F. A interdisciplinaridade na legislação educacional, no discurso acadêmico e na prática escolar do Ensino Médio: panaceia ou falácia educacional? Caderno Brasileiro de Ensino de Física, Florianópolis, v. 33, n. 1, p. 92-110, abr. 2016. 
MUENCHEN, C.; AULER, D. Abordagem temática: desafios na Educação de Jovens e Adultos. Revista Brasileira de Pesquisa em Educação em Ciências, Belo Horizonte, v. 7, n. $3,2007$.

NASSAR, A. B. et al. A física e os novos rumos da engenharia na Amazônia Revista Brasileira de Ensino de Física, São Paulo, v. 30, n. 1, 1307, mar. 2008.

NORONHA, D. P.; FERREIRA, S. M. S. P. Revisões de literatura. In: CAMPELLO, B. S.; CONDÓN, B. V.; KREMER, J. M. (Orgs.) Fontes de informação para pesquisadores e profissionais. Belo Horizonte: UFMG, 2000.

OZELAME, D. M.; ROCHA FILHO, J. B. As dificuldades docentes em desenvolver práticas interdisciplinares no ensino de Ciências e Matemática. Revista Acta Scientiae, Canoas, v. 18, n. 1, p. 239-249, jan.-abr. 2016.

PAVIANI, J. Interdisciplinaridade: conceitos e distinções. 2. ed. Caxias do Sul: EDUCS, 2008.

PIERSON, A. H. C.; NEVES, M. R. Interdisciplinaridade na formação de professores de Ciências: conhecendo obstáculos. Revista Brasileira de Pesquisa em Educação em Ciências, Belo Horizonte, v. 1, n. 2, p. 120-131, 2011.

PIMENTEL, J. R. et al. Uma sugestão para a interação multidisciplinar: a observação do fenômeno da fluorescência. Caderno Brasileiro de Ensino de Física, Florianópolis, v. 31, n. 2, p. 365-384, ago. 2014.

POMBO, O. Interdisciplinaridade: conceito, problemas e perspectivas. In: A interdisciplinaridade: reflexão e experiência. Lisboa. 1993. Recuperado de: $<$ http://www.educ.fc.ul.pt/docentes/opombo/mathesis/inter disciplinaridade.pdf $>$.

POMBO, O. Interdisciplinaridade: Ambições e Limites. Lisboa: Relógio D'água Editores, 2004.

POMBO, O. Epistemologia da Interdisciplinaridade. Universidade Estadual do Oeste do Paraná. Revista Ideação, Foz do Iguaçu, v. 10, n. 1, p. 90-40, 2008.

RAMOS, J. T. J.; SILVA, A. M. T. B. da. As concepções dos professores sobre a interdisciplinaridade em um modelo alternativo de formação em ciências exatas: possíveis convergências. Revista Investigações em Ensino de Ciências, Porto Alegre, v. 23, n. 3, p. 
$01-30,2018$

REGIANI, A. M. et al. Seguindo os passos de Sherlock Holmes: experiência interdisciplinar em encontro de divulgação científica. Revista Ensaio Pesquisa em Educação em Ciências, Belo Horizonte, v. 14, n. 03, p. 185-198, set-dez, 2012.

REZENDE, F.; GARCIA, M. A. C.; COLA, C. S. D. Desenvolvimento e avaliação de um sistema hipermídia que integra conceitos básicos de Mecânica, Biomecânica e Anatomia Humana. Revista Investigações em Ensino de Ciências, Porto Alegre, v. 11, n. 2, p. 239259, 2006.

RICARDO, E. C.; ZYLBERSZTAJN, A. Os Parâmetros Curriculares Nacionais na formação inicial dos professores das Ciências da Natureza e Matemática do Ensino Médio. Revista Investigações em Ensino de Ciências, Porto Alegre, v. 12, n. 3, p. 339-355, 2007.

ROCHA FILHO, J. B. et al. Medição da carga elementar por eletrólise da água. Caderno Brasileiro de Ensino de Física, Florianópolis, v. 26, n. 2, p. 328-341, ago. 2009.

ROEHRIG, S. A. G.; CAMARGO, S. Educação com enfoque CTS em documentos curriculares regionais: o caso das diretrizes curriculares de Física do estado do Paraná. Revista Ciência \& Educação, Bauru, v. 20, n. 4, p. 871-887, 2014.

ROSO, C. C.; AULER, D. A participação na construção do currículo: práticas educativas vinculadas ao movimento CTS. Revista Ciência \& Educação, Bauru, v. 22, n. 2, p. 371-389, 2016.

ROSO, C. C. et al. Currículo temático fundamentado em Freire-CTS: engajamento de professores de física em formação inicial. Revista Ensaio Pesquisa em Educação em Ciências, Belo Horizonte, v.17, n. 2, p. 372-389, maio-ago. 2015.

ROTHBERG, D.; QUINATO, G. A. C. Ensino de Ciências e CTS: contribuições ao aperfeiçoamento de situações de aprendizagem sobre Entropia e Degradação de Energia. Alexandria Revista de Educação em Ciência e Tecnologia, Florianópolis, v. 9, n. 1, p. 179206, maio 2016.

SANTAROSA, M. C. P. Os lugares da Matemática na Física e suas dificuldades contextuais: implicações para um sistema de ensino integrado. Revista Investigações em Ensino de Ciências, Porto Alegre, v. 18, n. 1, p. 215-235, 2013. 
SANTAROSA, M. C. P.; MOREIRA, M. A. O Cálculo nas aulas de Física da UFRGS: um estudo exploratório. Revista Investigações em Ensino de Ciências, Porto Alegre, v. 16, n. 2, p. 317-351, 2011.

SANTOMÉ, J. T. Globalização e interdisciplinaridade: o currículo integrado. Tradução: Cláudia Schilling. Porto Alegre: Editora Artes Médicas Sul Ltda., 1998.

SANTOS, C. A.; VALEIRAS, N. Currículo interdisciplinar para licenciatura em ciências da natureza. Revista Brasileira de Ensino de Física, São Paulo, v. 36, n. 2, 2504, jun. 2014.

SESTARI, F. B. et al. Concepções docentes sobre Ensino Médio Integrado e Interdisciplinaridade: estudo de caso em um Curso Técnico em Agropecuária do Instituto Federal do Rio Grande do Sul. Research, Society and Development, v. 9, n. 8, e624985790, 2020. Disponível em: <https://doi.org/10.33448/rsd-v9i8.5790>. Acesso em: out. 2020.

SEVERINO, A. J. O uno e o múltiplo: o sentido antropológico do interdisciplinar. In. JANTSCH, A. P.; BIANCHETTI, L. (Orgs.) Interdisciplinaridade: para além da filosofia do sujeito. 9. ed. atualizada e ampliada. Petrópolis: Vozes, p. 138-154, 2011.

SOUZA, M. C. A. et al. Disciplinas integradoras no currículo médico: uma inovação pedagógica. Revista Práxis, Volta Redonda, v. 10, n. 19, jun. 2018.

STADLER, J. P.; HUSSEIN, F. R. G. S. O perfil das questões de ciências naturais no novo Enem: interdisciplinaridade ou contextualização. Revista Ciência \& Educação, Bauru, v. 23, n. 2, p. 391-402, 2017.

VILLANI, A.; FRANZONI, M.; VALADARES, J. M. Desenvolvimento de um grupo de licenciandos numa disciplina de prática de ensino de Física e Biologia. Revista Investigações em Ensino de Ciências, Porto Alegre, v. 13, n. 2, p. 143-168, 2008.

WIRZBICKI, S. M.; ZANON, L. B. Abordagens e Reflexões sobre o Ensino do conceito Energia nas transformações dos alimentos. Alexandria Revista de Educação em Ciência e Tecnologia, Florianópolis, v. 5, n. 3, p. 195-218, nov. 2012. 